\title{
Evaluation of the Multi-Structural Potential of Ni-Co/SiC Nanocomposite Coatings Electrodeposited in API 5L X80 Steel
}

\author{
Roseana F. da C. Pereira ${ }^{a *}$ (D), Edkarlla S. D. de Oliveira ${ }^{a}$ (D, Maria Alice G. de A. Lima ${ }^{b}$, \\ Severino L. Urtiga Filho ${ }^{a}$

\begin{abstract}
${ }^{a}$ Universidade Federal de Pernambuco, Departamento de Engenharia Mecânica, Avenida Professor Moraes Rego, 1235, Cidade Universitária, 50670-901, Recife, PE, Brasil

${ }^{b}$ Universidade Federal de Pernambuco, Departamento de Engenharia Quimica, Av. Prof. Arthur Sá,
\end{abstract} \\ Cidade Universitária, 50740-521, Recife, PE, Brasil
}

Received: August 10, 2020; Revised: November 15, 2020; Accepted: December 20, 2020

\begin{abstract}
The use of nanocomposite coatings on carbon steel has been very promising. In this paper, the formation mechanism of multilayer of $\mathrm{Ni}-\mathrm{Co} / \mathrm{SiC}$ nanocomposite coating electrodeposited in $\mathrm{API} 5 \mathrm{~L}$ $\mathrm{X} 80$ steel was investigated. The coatings were obtained by galvanostatic deposition technique using a single bath and a single cathodic current density value. The results showed a variation in morphology and chemical composition of the coatings both on the surface and along the cross-section at all time conditions tested, confirming the functional gradient of the coating. The formation of the $\mathrm{Ni}-\mathrm{Co} / \mathrm{SiC}$ nanocomposite coating occurred through the multilayer deposition mechanism, with compositions mostly alternated between $\mathrm{Ni}$ and $\mathrm{Co}$. The preferred orientation of the plane (220) and phase structure FCC remained constant on the surface of all the obtained samples. It was observed that the coating became more compact in the region located closer to the substrate, where an increase in micro-hardness was observed.
\end{abstract}

Keywords: $\mathrm{Ni}-\mathrm{Co} / \mathrm{SiC}$ nanocomposite, functionally graded coatings, multiple layers, galvanostatic deposition, API 5 L X80 steel.

\section{Introduction}

During the last few decades, nanocomposite coatings became widely used in many strategic areas in the industry due to its unique mechanical properties, self-lubricity, thermal stability, oxidation, corrosion and wear resistance ${ }^{1,2}$. So far, many techniques have been employed to produce nanocomposite coatings, including: powder metallurgy, foil diffusion bonding, stir casting, spray deposition, physical vapor deposition, as well as electrolytic deposition ${ }^{3,4}$. Electrodeposition is relatively simple to control, efficient, low initial capital investment and high quality, when compared to other techniques ${ }^{5,6}$.

The obtention of $\mathrm{Ni}-\mathrm{Co} / \mathrm{SiC}$ nanocomposite coatings by electrodeposition comes from the addition of $\mathrm{SiC}$ nanoparticles to an electrolytic bath composed of $\mathrm{Ni}$ and Co salts ${ }^{7}$. The incorporation of nanoparticulate $\mathrm{SiC}$, which has high micro-hardness, good stability and resistance to wear and corrosion at high temperatures, to the Ni-Co metal matrix can provide unique properties to $\mathrm{Ni}-\mathrm{Co} / \mathrm{SiC}$ coatings ${ }^{8,9}$. This inclusion provides a diversity of applications of $\mathrm{Ni}$ Co-based composite coatings in the automotive, aerospace, automotive, petrochemical and other industries due to its good adhesion to the substrate, low residual stress, low porosity, high hardness, anti-wear and anti-corrosion properties ${ }^{1,4,10}$.

The electrodeposition of $\mathrm{Ni}-\mathrm{Co}$ matrix coatings is governed by the anomalous co-deposition of $\mathrm{Ni}^{2+}$ and $\mathrm{Co}^{2+}$

*e-mail: roseana94@gmail.com. ions, whose reduction in the cathode generates intermediate species that alter the bath composition, the coating surface and the incorporation of nanoparticles ${ }^{6,9}$. The variation of process parameters such as current density, stirring rate, and composition in the bath causes changes and can influence the system producing multi-structured coatings with a functional gradient, consisting of multiple layers with different compositions $s^{5,11,12}$. Studies in the area of multistructured coatings have been carried out to improve the performance of the coating, which leads to a wide variety of applications. Functionally graded composite coatings constitute a class of materials whose surface and interface properties can function efficiently due to the gradual variation of the particle content with the coating thickness in order to satisfy specific needs ${ }^{4,11,13}$.

The growing interest in research on $\mathrm{Ni}-\mathrm{Co} / \mathrm{SiC}$ nanocomposite coatings shows that it is possible to obtain these electrodeposits on several metallic surfaces, such as copper, aluminum, sintered $\mathrm{NdFeB}$ material and mild steel,

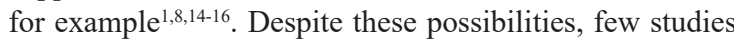
have been focused on obtaining nanocomposite coating in carbon steel wich is a very important material in the industry and requires protection. The $\mathrm{Ni}-\mathrm{Co} / \mathrm{SiC}$ nanocomposite coating was the subject of a previous study ${ }^{16}$ that showed excellent corrosion resistance and hardness properties when applied to API 5L X80 steel, a material used in pipelines in the oil industry. Yang and Cheng ${ }^{4}$ studied the application of 
the coating against erosion-enhanced corrosion of carbon steel pipes in oilsand slurry. Lari Baghal, Heydarzadeh Sohi and Amadeh $^{15}$ tested the application of this coating on aluminum pistons for engine, utilized under fairly high temperature and wearing conditions, and found promising results. Furthermore, it is important that electrodeposition is studied on several substrates due to the influence of hydrogen production reaction ${ }^{17,18}$

Most studies about this theme are focused on a singlelayer $\mathrm{Ni}-\mathrm{Co} / \mathrm{SiC}$ nanocomposite coatings obtained by electrodeposition. However, there has never been any study conducted to examine the potential of multi-structural coating on any substrate, much less in carbon steel. Moreover, not enough emphasis has been put on studying the crosssectional areas and their characteristics such as morphology, composition, and properties such as micro-hardness. This study is made relevant because it aims to explore the possibility of obtaining a multi-structured coating of $\mathrm{Ni}-\mathrm{Co} / \mathrm{SiC}$, in a steel substrate, and to provide information to clarify the process of formation of multiple layers. Additionally, this work intends to investigate the formation mechanism of multilayer of $\mathrm{Ni}-\mathrm{Co} / \mathrm{SiC}$ nanocomposite coating electrodeposited in API $5 \mathrm{~L} \mathrm{X80} \mathrm{steel.} \mathrm{The} \mathrm{coatings} \mathrm{were} \mathrm{obtained} \mathrm{by} \mathrm{galvanostatic}$ deposition technique using a single bath and a single cathodic current density value. Morphology, chemical composition and micro-hardness of the surface and the cross-section of the coatings were studied and related to multi-structural potential of samples.

\section{Experimental Procedure}

\subsection{Substrate preparation}

API 5L X80 steel pipeline was cut into $15 \mathrm{~mm} \times 10 \mathrm{~mm}$ x $6 \mathrm{~mm}$ specimens with this chemical composition (\%): C 0.030, S 0.004, Cr 0.159, Mn 1.72, Si 0.170, Al 0.028 and residual Fe. All specimens had their sides sealed with epoxy resin, and a rectangular work area of $1.5 \mathrm{~cm}^{2}$ was left and prepared to receive the coatings. Before electroplating, the working face was ground sequentially with 220, 320, 400 and 600 grit emery papers and polished with a $1 \mu \mathrm{m} \mathrm{Al}_{2} \mathrm{O}_{3}$ powder suspension ${ }^{4}$. Then, the specimens were cleaned in an electrolyte containing $30 \mathrm{~g} / \mathrm{L} \mathrm{Na}_{2} \mathrm{CO}_{3}$ and $10 \mathrm{~g} / \mathrm{L} \mathrm{NaOH}$ at room temperature $\left(\sim 25^{\circ} \mathrm{C}\right)$, and activated in $1: 1(\mathrm{v} / \mathrm{v})$ $\mathrm{HCl}$ solution for $20 \mathrm{~s}^{19}$.

\subsection{Electrolyte and electrodepositing parameters}

The electrolytic bath compositions and plating parameters used in electrodepositions are shown in Table 1. SiC nanoparticles $(50-60 \mathrm{~nm})$ were obtained from IoLi.Tec Ionic Liquids Technologies $\mathrm{GmbH}^{\circledR}$ and used as received with any modification. All the chemicals used in the experiment were analytical reagent and deionized water as solvent. The electrolyte bath was stirred magnetically with $600 \mathrm{rpm}$ for 24 hours beforehand and was done during the plating in order to achieve a homogeneous dispersion and full suspension of nanoparticles during electrodeposition ${ }^{20}$.

In ordem to investigate the deposition of multilayers and the formation mechanism of the coating nanocomposite $\mathrm{Ni}-\mathrm{Co} / \mathrm{SiC}$, the following deposition times were used: 10 ,
20, 30, 40, 50 and $60 \mathrm{~min}$. The coatings were obtained by galvanostatic deposition technique using a single bath and a single cathodic current density value $\left(5.5 \mathrm{~A} \mathrm{dm}^{-2}\right)$. The cathodic current density value was defined by a previous study and corresponded to the current condition, wich was able to obtain the coating with the best properties for this system $^{16}$. The bath $\mathrm{pH}$ was maintained at 4.5 , it was adjusted with $\mathrm{NH}_{4} \mathrm{OH}$ or $\mathrm{H}_{2} \mathrm{SO}_{4}$ when necessary ${ }^{7}$. The temperature of the electrolytic bath and stirring rate were maintained at $55^{\circ} \mathrm{C}$ and $600 \mathrm{rpm}$, respectively. Electrodeposition was performed using a conventional electrochemical cell made of Pyrex ${ }^{\circledR}$ glass that contained an electrolytic bath, in which the steel specimen was inserted as a cathode and the platinum electrode as an inert anode, at a distance of $3 \mathrm{~cm}$ from each other. Each sample was obtained in a bath and used only once, so as to ensure the same conditions as in Table 1 for all coatings. The current control was performed by an AUTOLAB ${ }^{\circledR}$ Galvanostat/Potentiostat, controlled by the Nova 1.11 Program. All the obtained samples were washed by ultrasonic stirring for about $8 \mathrm{~min}$ to remove any weakly adsorbed $\mathrm{SiC}$ nanoparticles.

\subsection{SEM and EDS characterization}

The morphology and the chemical composition on the surface and cross-section of deposits were analyzed using a model Tescan ${ }^{\circledR}$ Mira 3 Scanning Electron Microscopy coupled with Energy Dispersive Spectroscopy (SEM-EDS). For the analysis of the coating profile, each sample was embedded, so its cross-section was subjected to metallographic preparation. The chemical composition was examined in cross-section at depths of $10 \mu \mathrm{m}, 20 \mu \mathrm{m}$ and $30 \mu \mathrm{m}$, as it was measured in relation to the coating surface level. The thickness of the deposits was determined by the arithmetic average of 5 measurements ${ }^{21}$. With a view to understand the mechanism of coating formation, the cross-sectional samples were etched in a solution of nitric acid $\left(\mathrm{HNO}_{3}\right)$ and acetic acid $\left(\mathrm{CH}_{3} \mathrm{COOH}\right)(1: 1)$ for $5 \mathrm{~s}^{22}$.

\subsection{XRD characterization}

X-Ray Diffraction measurements were carried out by using a Shimadzu ${ }^{\circledR}$ XRD-7000 diffractometer employing $\mathrm{Cu} \mathrm{K} \alpha$ radiation of wavelength $0.154 \mathrm{~nm}$. The scan rate was $0.05^{\circ}$ per second over a $2 \theta$ ranging from $20^{\circ}$ to $100^{\circ} 23$.

Table 1. Electrolyte composition and plating parameters for depositing $\mathrm{Ni}-\mathrm{Co} / \mathrm{SiC}$ nanocomposite.

\begin{tabular}{lc}
\hline \multicolumn{1}{c}{ Compositions and conditions } & Parameters \\
\hline $\mathrm{NiSO}_{4} \cdot 7 \mathrm{H}_{2} \mathrm{O}\left(\mathrm{g} \mathrm{L}^{-1}\right)$ & 200 \\
\hline $\mathrm{NiCl}_{2} \cdot 6 \mathrm{H}_{2} \mathrm{O}\left(\mathrm{g} \mathrm{L}^{-1}\right)$ & 70 \\
\hline $\mathrm{CoSO}_{4} \cdot 7 \mathrm{H}_{2} \mathrm{O}\left(\mathrm{g} \mathrm{L}^{-1}\right)$ & 60 \\
\hline Sodium citrate $\left(\mathrm{g} \mathrm{L}^{-1}\right)$ & 30 \\
\hline Boric acid $\left(\mathrm{g} \mathrm{L}^{-1}\right)$ & 30 \\
\hline SiC nanoparticles 50-60 nm $\left(\mathrm{g} \mathrm{L}^{-1}\right)$ & 30 \\
\hline Electrodeposition time $(\mathrm{min})$ & $10,20,30,40,50,60$ \\
\hline Cathodic current density $\left(\mathrm{A} \mathrm{dm}^{-2}\right)$ & 5.5 \\
\hline $\mathrm{pH}$ & $4.5 \pm 0,1$ \\
\hline Temperature $\left({ }^{\circ} \mathrm{C}\right)$ & $55 \pm 1$ \\
\hline Stirring speed $(\mathrm{rpm})$ & 600 \\
\hline
\end{tabular}


Crystalline structure, texture coefficient (TC) and grain size were determined on the surface of the deposits ${ }^{24}$.

\subsection{Micro-hardness measurement}

The Vickers micro-hardness was measured on the surface and cross-section of the coatings using a Vickers diamond indenter. On the surface, the applied load was $200 \mathrm{~g}$ for $15 \mathrm{~s}$ and in the cross-section it was $10 \mathrm{~g}$ for $15 \mathrm{~s}^{19}$. This decrease in load made it possible to determine the micro-hardness at various points in the cross-section and, thus, to establish its variation along the thickness. Ten measurements were conducted on each sample to obtain the average value ${ }^{25}$. Each profile was performed in a diagonal line with reference to the surface of the coating, from where the indentations started.

\section{Results and Discussion}

\subsection{Surface characterization}

Figures 1 and 2 show, respectively, the surface morphology and chemical composition of $\mathrm{Ni}-\mathrm{Co} / \mathrm{SiC}$ nanocomposite coatings obtained by galvanostatic deposition within 10, 20, $30,40,50$ and $60 \mathrm{~min}$. Figure 3 shows the XRD spectrum of the sample surface obtained in a deposition time of $10 \mathrm{~min}$ and $20 \mathrm{~min}$, and Table 2 shows the texture coefficient (TC) and grain size calculated from the diffractograms, based on the plane (220).

In Figure 1, it can be seen that the substrate surface was coated in all samples. The morphology observed in Figure 1 and the chemical composition of the coating shown in Figure 2 varied considerably depending on the deposition time of the electrolyte components. In Figure 1-A, it can be seen that the coating obtained within 10 min presented a branched, acicular structure (needle-like), typical of cobalt and richcobalt solid solutions as shown in Figure 2. Moreover, it presented the highest grain size value $(96,37 \mathrm{~nm})$ among all samples (Table 2). The deposit formed after $10 \mathrm{~min}$ represents a high porosity layer, due to the empty spaces between the cobalt needle-like structures. These void spaces are partially filled with globular formations which are attributed to the deposition of SiC particles entrapped by nickel.

Figure 1B shows the presence of "cauliflower" structures attributed to nickel-rich coatings, indicating that on this surface, the noblest element (nickel) is in greater concentration despite the occurrence of anomalous codeposition in $\mathrm{Ni}-\mathrm{Co}$ matrix coatings ${ }^{9}$. The surface of the coating obtained after
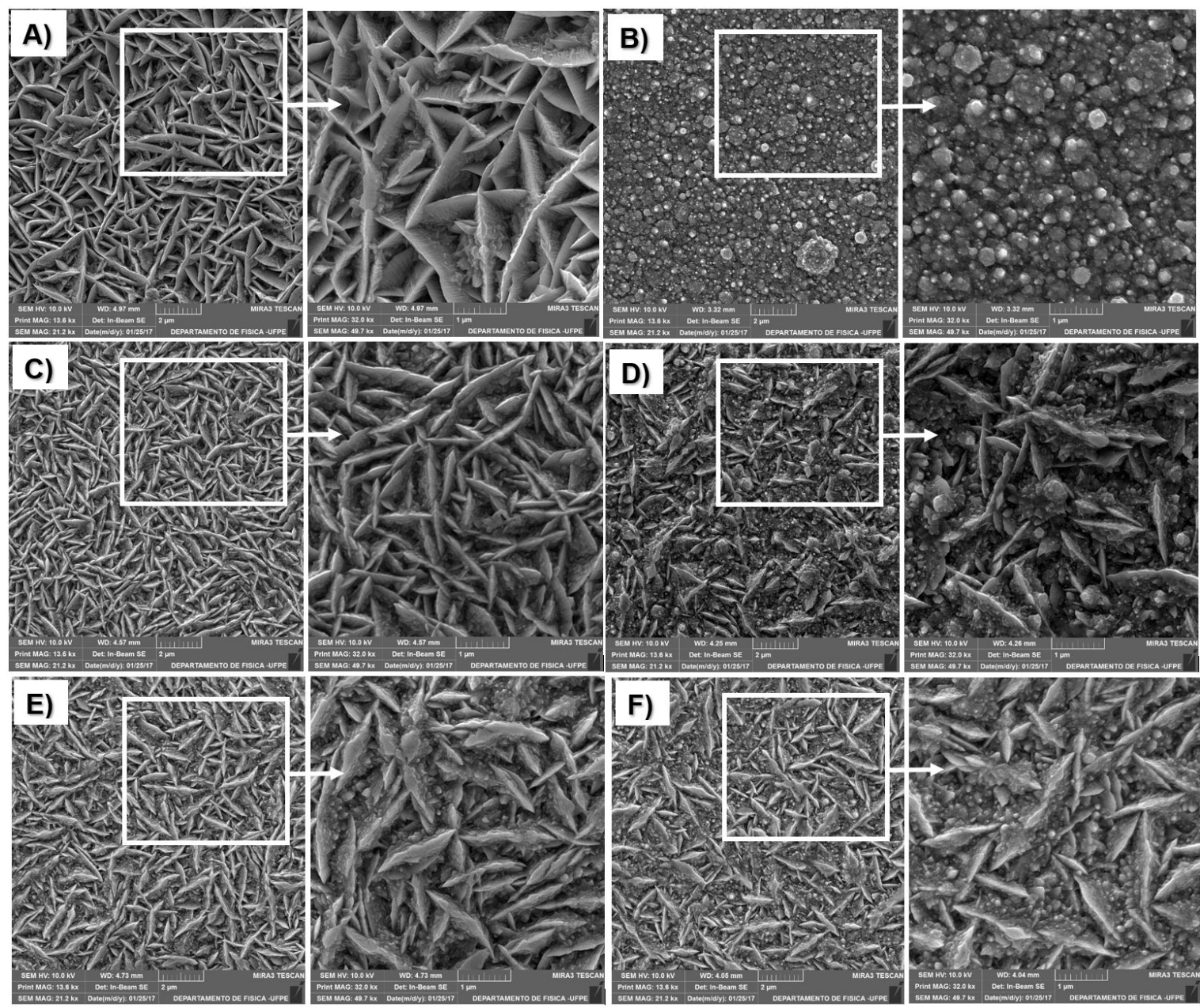

Figure 1. SEM morphology of $\mathrm{Ni}-\mathrm{Co} / \mathrm{SiC}$ coatings prepared at galvanostatic deposition of density current $5.5 \mathrm{~A} \mathrm{dm}^{-2}$ in the intervals: A) $10 \mathrm{~min}$; B) $20 \mathrm{~min}$; C) $30 \mathrm{~min}$; D) $40 \mathrm{~min}$; E) $50 \mathrm{~min}$; F) $60 \mathrm{~min}$. SEM magnifications of 21,2 kx (left) and 49,7 kx (right). 


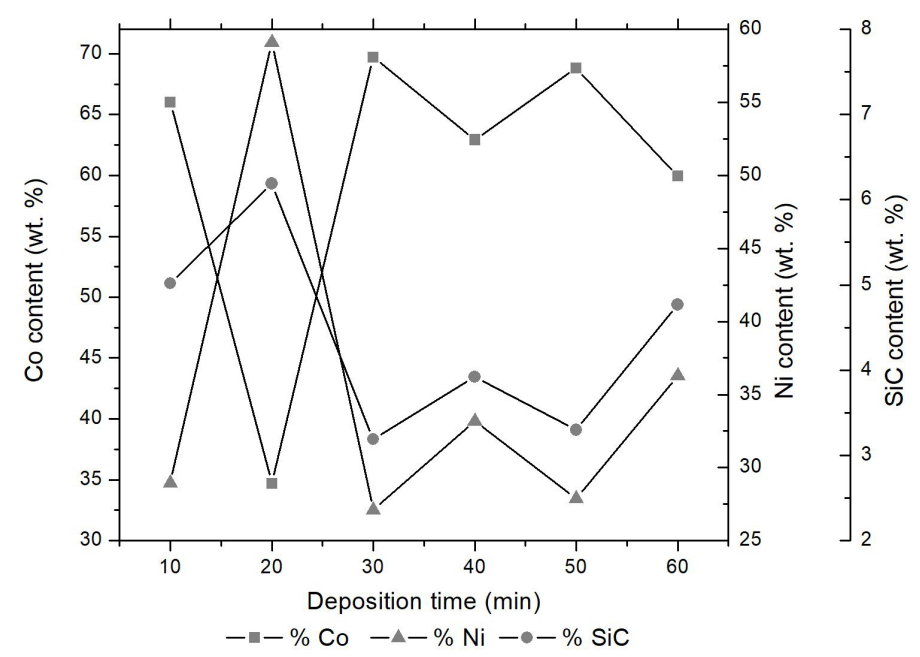

Figure 2. Percentage variation of the chemical composition of $\mathrm{Ni}-\mathrm{Co} / \mathrm{SiC}$ nanocomposites obtained at $5.5 \mathrm{~A} \mathrm{dm}^{-2}$ as a function of deposition time.
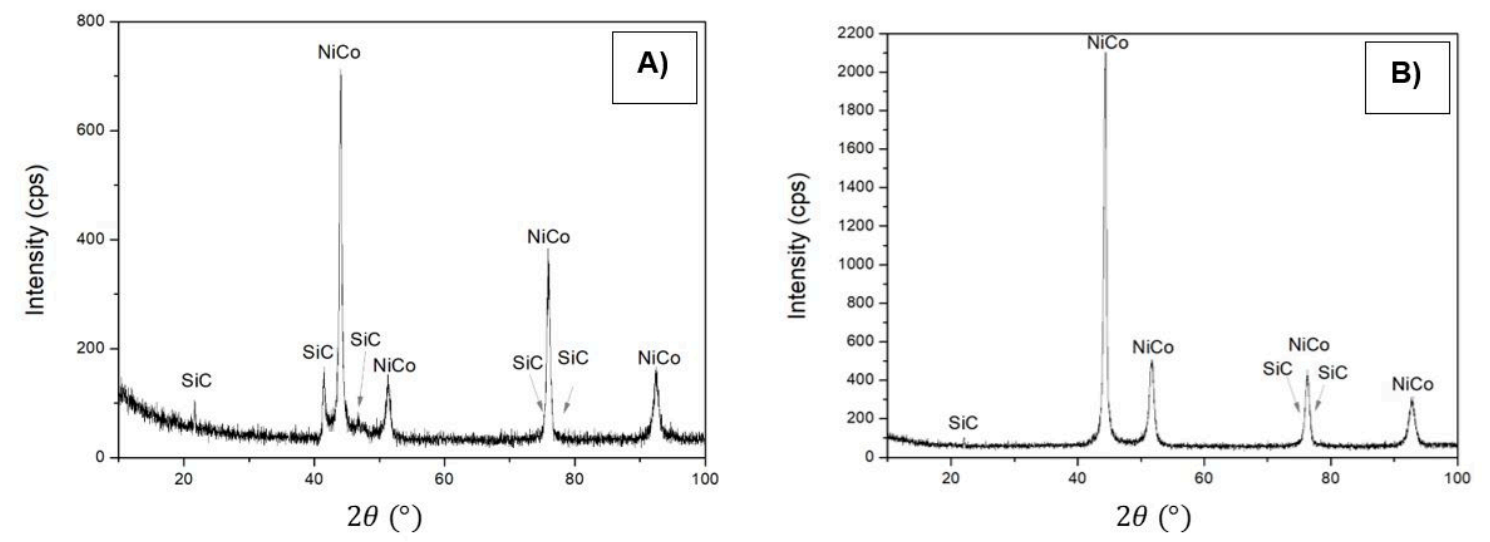

Figure 3. XRD diffractogram of $\mathrm{Ni}-\mathrm{Co} / \mathrm{SiC}$ nancocomposite coating. A) $10 \mathrm{~min}$; B) $20 \mathrm{~min}$.

Table 2. Effect of deposition time on grain size and texture coefficient for depositing $\mathrm{Ni}-\mathrm{Co} / \mathrm{SiC}$ nanocomposite.

\begin{tabular}{|c|c|c|c|c|c|}
\hline \multirow{2}{*}{$\begin{array}{l}\text { Deposition time } \\
\text { (min) }\end{array}$} & \multirow{2}{*}{ Grain size $(\mathrm{nm})$} & \multicolumn{4}{|c|}{ Texture coefficient $(\%)$} \\
\hline & & $(111)$ & $(200)$ & $(220)$ & $(311)$ \\
\hline 10 & 96.37 & 16.13 & 8.19 & 53.97 & 21.71 \\
\hline 20 & 38.97 & 26.46 & 15.09 & 35.46 & 22.97 \\
\hline 30 & 57.82 & 15.73 & 6.81 & 56.33 & 21.12 \\
\hline 40 & 46.26 & 23.82 & 13.58 & 40.38 & 22.20 \\
\hline 50 & 77.10 & 16.63 & 8.35 & 50.09 & 24.91 \\
\hline 60 & 53.97 & 18.24 & 8.17 & 49.95 & 23.64 \\
\hline
\end{tabular}

20 min of deposition (Figure 1B) showed a morphology that was completely different from the coating obtained within $10 \mathrm{~min}$ (Figure 1A). In this sense, it had a significant reduction in the grain size that reached the lowest value among the analyzed samples. , about $38.97 \mathrm{~nm}$ (Table 2). This $59 \%$ reduction in grain size in relation to the $10 \mathrm{~min}$ sample is due to the distinct characteristics between the surfaces of the coatings formed after $10 \mathrm{~min}$ and $20 \mathrm{~min}$. This result is supported by the chemical composition (Figure 2) of the sample obtained after $20 \mathrm{~min}$, which presented the highest nickel (59 wt.\%) and $\mathrm{SiC}$ (6.2 wt.\%) contents, when compared to all the investigated samples. This indicates that nickel, whose deposition occurred among the spaces of cobalt needle-like structures, filled the spaces forming a new surface with a different morphology. According to Rudnik and Syrek, cobalt deposition provides surface roughness for nickel deposition and $\mathrm{SiC}$ trapping ${ }^{23}$. The presence of nickel in the coating structure tends to work by reducing the void spaces among the cobalt structures and, consequently, reducing the grain size $e^{4}$.

With 30 min of deposition time (Figure 1C), the surface of the coating again presented, once more, structures in the 
form of typical cobalt needle-like. However, the dimensions were smaller than the structures of the sample obtained within $10 \mathrm{~min}$ (Figure 1A). Another characteristic observed in the coating at $30 \mathrm{~min}$, was the surface porosity reduction when compared to the $10 \mathrm{~min}$ condition, due to the greater amount of globular formations (nickel and $\mathrm{SiC}$ ) among the cobalt structures. These results indicate that the coating formed at $30 \mathrm{~min}$ is richer in cobalt (Figure 2) and it has a larger grain size when compared to the 20 min condition. At 40, 50 and 60 min (Figures 1D, 1E and 1F), the morphology and the chemical composition percentage of the surface coatings (Figure 2) varied at each time interval with alternations between richer structures of cobalt or nickel and SiC. The increase in the cobalt content deposited on the sample surface resulted in a decrease in the other two components in the final coating, and so on. The increase in the cobalt content produces a surface with greater roughness and a larger grain size. Meanwhile, the elevation of nickel and $\mathrm{SiC}$ content fills the void spaces on the surface through the deposition of these components in the irregularities caused by the presence of cobalt in the previous layer and, therefore, resulting in a smaller grain size. Although there were variations in the amounts of $\mathrm{Co}, \mathrm{Ni}$ and $\mathrm{SiC}$ deposited on the surfaces obtained after $40 \mathrm{~min}$, the deposits morphology observed in Figures 1D, 1E and $1 \mathrm{~F}$ was similar.

The different morphologies obtained over the deposition time indicate that the electrodeposition of the coating occurred through the formation of layers composed mainly of cobalt or nickel, contrasting with what was expected by the anomalous codeposition, wich is a characteristic of metals in the iron group $(\mathrm{Ni}, \mathrm{Co} \text { e } \mathrm{Fe})^{10}$. In the present work, the less noble element (cobalt), despite being in a lower proportion in the electrolytic bath (17 wt.\%), did not deposit preferentially to nickel all the time. Nickel deposition is thermodynamically favored over cobalt, although their reduction potentials are close, their thermodynamics indicate that they would deposit in an approximate proportion to the concentrations in the electrolytic bath ${ }^{9}$. The nickel deposition occurs in a single stage, transfering electrons to the active nickel species, resulting metallic nickel, according to Equation $1^{26}$ :

$$
\mathrm{Ni}^{2+}+2 e^{-} \rightarrow \mathrm{Ni}_{(s)} \quad E^{0}=-0.25 \mathrm{~V} v \mathrm{SCE}
$$

Some active nickel species complex with the citrate ions present in the bath, generating another active species $\mathrm{NiCit}^{-}$, which will slowly, also provide a reduction of metallic nickel on the substrate, as described in Equation 2 presented below:

$$
\mathrm{NiCit}^{-}+2 e^{-} \rightarrow \mathrm{Ni}(s)+\mathrm{Cit}^{3-}
$$

With the nickel deposition, the hydrogen evolution reaction starts simultaneously as shown in Equation $3^{27}$ :

$$
2 \mathrm{H}_{2} \mathrm{O}+2 e^{-} \rightarrow \mathrm{H}_{2}+2 \mathrm{OH}^{-} \quad E^{0}=-0.414 \mathrm{~V} v \mathrm{SCE}
$$

Unlike nickel, whose reduction occurs in a single phase, the deposition of cobalt occurs through a two-stage electron transfer: the first stage corresponds to the reduction of free $\mathrm{Co}^{2+}$ ions to $\mathrm{Co}^{+}$ions and the second stage is a rapid process of reducing monovalent ions to metallic cobalt, according to Equations 4 and 5, respectively ${ }^{28}$ :

$$
\begin{aligned}
& \mathrm{Co}^{2+}+1 e^{-} \rightarrow \mathrm{Co}_{(a d s)}^{+} \quad E^{0}=-0.28 \mathrm{Vvs} S C E \\
& \mathrm{Co}_{(\text {ads })}^{+}+1 e^{-} \rightarrow \mathrm{Co}_{(s)}
\end{aligned}
$$

Similarly to nickel in Equation 2, some $\mathrm{Co}^{2+}$ ions will be complexed to citrate, so that this $\mathrm{CoCit}^{-}$complex ion will favor the cobalt reduction on the surface as shown in Equation 6:

$$
\mathrm{CoCit}^{-}+2 e^{-} \rightarrow \mathrm{Co}_{(s)}+\mathrm{Cit}^{3-}
$$

Over time, $\mathrm{CoCit}^{-}$diffusive complex ions reach the electrode more slowly. The delayed reduction is also associated with purely chemical processes prior to the reduction itself, and dissociation of the adsorbed complex 9 . Although the reactions presented above indicate greater ease of nickel deposition, in $\mathrm{Ni}-\mathrm{Co} / \mathrm{SiC}$ coatings obtained within $10 \mathrm{~min}, 30 \mathrm{~min}$ and $50 \mathrm{~min}$ (Figure 2), a highly preferential deposition of cobalt occurred. This occurrence is attributed to the formation and adsorption $\mathrm{MOH}^{+}$metal hydroxides due to the increase of $\mathrm{pH}$ near the cathode surface ${ }^{29}$. The hydrogen evolution reaction (Equation 3 ) causes an increase in the concentration of $\mathrm{OH}^{-}$near the surface of the cathode. Consequently, mono-metallic hydroxides $\mathrm{MOH}^{+}$are formed and adsorbed on the surface of the deposit. Since the $\mathrm{Co}^{2+}$ ion is more reactive than the $\mathrm{Ni}^{+2}$ ion, more hydroxylated cobalt species will be formed and available to be adsorbed on the surface. Thus, the high Co content in the coating is associated with greater adsorption of $\mathrm{Co}(\mathrm{OH})^{+}$, when compared to the $\mathrm{Ni}(\mathrm{OH})^{+}$species $^{26}$. The $\mathrm{OH}^{-}$free ions complex to the $\mathrm{Co}^{2+}$ and $\mathrm{Ni}^{2+}$ ions, forming $\mathrm{Co}(\mathrm{OH})_{a d s}^{+}$and $\mathrm{Ni}(\mathrm{OH})_{a d s}^{+}$, respectively. The $\mathrm{Co}(\mathrm{OH})_{a d s}^{+}$adsorb on the cathode more easily than $\mathrm{Ni}(\mathrm{OH})_{a d s}^{+}$, simultaneously reducing for $\mathrm{Co}_{(\mathrm{s})}$, as well as blocking deposition sites. Hence, there is a reduction in the species deposition rate $\mathrm{Ni}$ according to Equation 7 , where $M$ represents $\mathrm{Co}$ or $\mathrm{Ni}$ atoms ${ }^{27}$. The ion $\mathrm{OH}^{-}$formed at the end of the reaction favors the formation of $M(\mathrm{OH})^{+}$ and improves the adsorption of $M(\mathrm{OH})_{a d s}^{+}$

$$
\mathrm{M}^{2+}+\mathrm{OH}^{-} \rightarrow \mathrm{M}(\mathrm{OH})^{+} \rightarrow \mathrm{M}(\mathrm{OH})_{a d s}^{+}+2 e^{-} \rightarrow M_{(s)}+\mathrm{OH}^{-}
$$

According to the above reactions, it is possible to propose a multilayer formation mechanism where: (1) the initial layer of the $\mathrm{Ni}-\mathrm{Co} / \mathrm{SiC}$ nanocomposite coating obtained within 10 min of deposition is richer in cobalt and provides roughness for $\mathrm{SiC}$ adsorption and acts by lowering the surface energy to reduce nickel; (2) a second nickel-rich layer forms, filling the void spaces among the cobalt needles and trapping the $\mathrm{SiC}$ after $20 \mathrm{~min}$ (Figure 1-B); (3) in subsequent times, there is an alternation between layers rich in cobalt and nickelrich layers and $\mathrm{SiC}$, depositing sequentially and creating conditions for the next layer to be formed by filling the void spaces and promoting the densification of the coatings.

Normally, it is expected that during the electrodeposition, the variation of cathode current influences the composition of the coatings due to different energies provided to the migration of species. However, it has found that when maintaining a constant cathodic current density of $5.5 \mathrm{~A} \mathrm{dm}^{-2}$ and operating parameters for a conventional coating has been found that the electrodeposition process triggered a series of 
reactions that result in a coating formed from multiple layers, with a gradient functional. The advantage of a functionally graded coatings is the possibility of deflecting the direction of corrosion development and retarding the exposure of the substrate to the medium by sealing existing pores and defects ${ }^{30}$.

Analyzing Figure 3, the low intensity peaks in the range of $2 \theta$ between $20^{\circ}$ and $40^{\circ}$ and, specifically the peaks $42.68^{\circ}$; $45.72^{\circ} ; 75.36^{\circ}$ and $78.05^{\circ}$ are related to the presence of $\mathrm{SiC}$ with rhombohedral crystal structure. The high intensity peaks correspond to a solid two-phase solution, which is rich in $\mathrm{Ni}$ and $\mathrm{Co}$ since these active species are present in the electrolytic bath and form the composite matrix with face-centered cubic (FCC) crystalline structure. The Ni-Co matrix identified has preferential orientation (220) followed by the planes (111), (311) and (200) that correspond to the respective values of the diffraction angle $2 \theta$ of $44.46^{\circ}$; $76.26^{\circ} ; 92.62^{\circ}$ and $51.60^{\circ}$. The intensity of diffraction peaks showed the opposite behavior presented by the grain size, they increase considerably when there is grain refining as observed in samples with Ni-rich matrix (Figure 2). Similary to the grain size, the texture coefficient (TC) varied depending on the deposition time. For example, the lowest grain size value occurred on the deposited surface for $20 \mathrm{~min}$, whose TC values were higher for the planes (111) and (200), which are planes with high atomic density. Additionally, the TC of the plane (220) at the 20 min sample was the lowest of all samples and this plane has the lowest atomic density. The variation in galvanostatic deposition time did not affect neither the preferential orientation plane (220) nor the FCC structure phase, although the surfaces of the deposits have different morphologies and chemical compositions.

\subsection{Cross-section characterization}

Figure 4 shows the measurements related to the thickness of $\mathrm{Ni}-\mathrm{Co} / \mathrm{SiC}$ nanocomposite coatings formed at 10, 20, 30, 40, 50 and $60 \mathrm{~min}$ of electrodeposition.

In Figure 4, it can be seen that the values increase with the deposition time. According to Faraday's Law, the amount of all elements released at the cathode or anode during electrolysis is proportional to the amount of electrical charge that passes through the system from one electrode

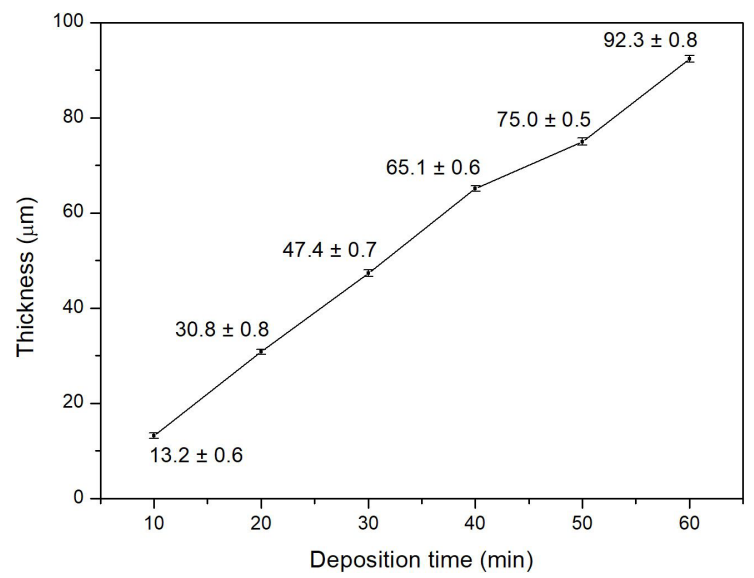

Figure 4. Average thickness of $\mathrm{Ni}-\mathrm{Co} / \mathrm{SiC}$ coatings obtained by galvanostatic deposition. to another ${ }^{6}$. When there is a galvanostatic deposition and a fixed value of cathodic current density is applied on the substrate, it allows the thickness to be directly proportional to the deposition time. Furthermore, the codeposition of inert particles such as $\mathrm{SiC}$, which are not reduced at the cathode, also contribute to the increase of the coating thickness, this process has been explained by a number of models. In this context, Brenner proposed a mechanism consisting of five consecutive steps for the codeposition of inert particles: (1) formation of ionic clouds in the particles; (2) the particle mass transfer by convection towards the cathode (substrate); (3) mass transfer of particles to the cathode surface by diffusion through a hydrodynamic boundary layer; (4) adsorption of the free ions and electroactive ions adsorbed on the particles in the cathode and, finally; (5) electroreduction of the adsorbed ions accompanied by the incorporation of the particles during the metallic matrix growth ${ }^{31}$. Guglielmi postulated that eletrocodeposition process occurs in two stages $^{32}$. Firstly, the particles are poorly adsorbed on the cathode surface by Van der Waals forces with a high degree of surface coverage, which can be described by Langmuir adsorption isotherm. Secondly, the particles are strongly adsorbed on the surface, by Coulomb forces under the effect of the applied electric field, and incorporated by the growth of the metallic matrix. Generally, the movement of ions and particles is controlled by an electric field and by the electrolyte agitation, these parameters were kept constant in this work ${ }^{4,28}$. For inert $\mathrm{SiC}$, the particles have to be trapped in the metal matrix, so it is necessary to form a "cloud" of cations adsorbed on the particle surface, which needs more energy than the free metal ions for convection and diffusion to the cathode surface. Furthermore, it must be considered that the deposition process of $\mathrm{SiC}$ particles depends on the coordination spheres formed around the surface of the nanoparticle ${ }^{6}$. The use of SiC nanoparticles allows a higher surface area for adsorption charge of ionic species present in the bath. Also, it favors the formation of coordination spheres around these particles. Owing to the affinity of the species (ionic or with partial polarization, in the case of water) with the SiC particle, it will present different diffusion rates to reach the substrate, depending on the type of active species involved $\left(\mathrm{Co}^{2+} ; \mathrm{Ni}^{2+} ; \mathrm{H}_{2} \mathrm{O}\right)$. Studies indicate that the incorporation of the ceramic phase in the coating can be improved as the most noble element is deposited, which was observed in Figure $2^{2,15,20}$. According Rudnik and Syrek, the "cloud" of adsorbed cation on the surface of $\mathrm{SiC}$ can ensure electrostatic attraction between particles and the cathode, but only the reduction of these metal ions assures permanent and stable insertion of nanoparticulate in the matrix metallic ${ }^{23}$. Also, according to the authors, this incorporation is seriously dependent on the current density and hydrodynamic conditions, which, in turn, determine the time of adhesion to the cathode surface, which must be sufficient for its incorporation. In the present work, the concentration of nanoparticulate $\mathrm{SiC}$ added to the electrolytic bath was $30 \mathrm{~g} / \mathrm{L}$. When baths with a high concentration of particles are used, there is a greater possibility that the particles will adsorb on the coating and, consequently, the deposits will have higher $\mathrm{SiC}$ contents ${ }^{4}$. However, in these baths, particle agglomeration can become a problem, as 
the uniform distribution of the reinforcement phase in the matrix is difficult ${ }^{20}$. For this reason, the electrolytic bath preparation occurred with the nanoparticles suspension in the bath through magnetic stirring for 24 hours prior to the deposition. Figure 5 shows the micrographs of the crosssection obtained by SEM after etching.

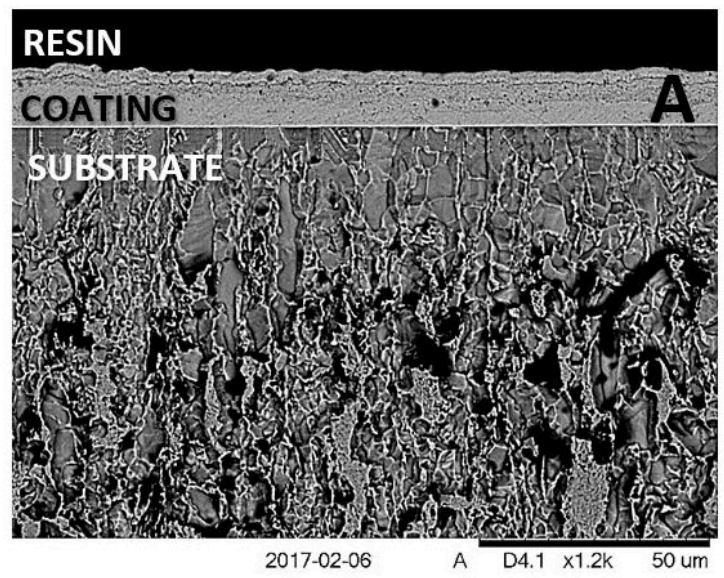

DEMECICTG
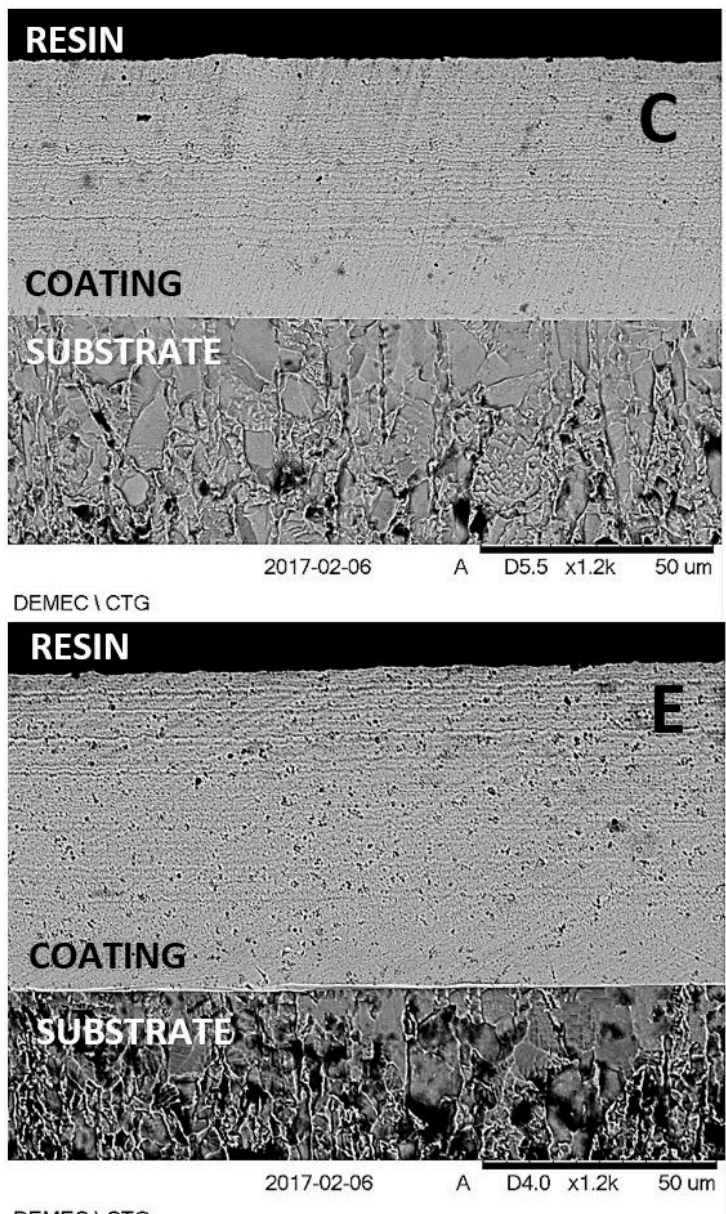

DEMECICTG
In Figure 5 it can be seen that the coatings were adhered. Moreover, they showed a uniform thickness and were formed by dense fine-grained structures. A well-defined interface between the coating and the substrate (API 5L X80 steel) is clearly seen in all samples. Along the cross-section it is possible to check the delimitation of the multiple and intermediate

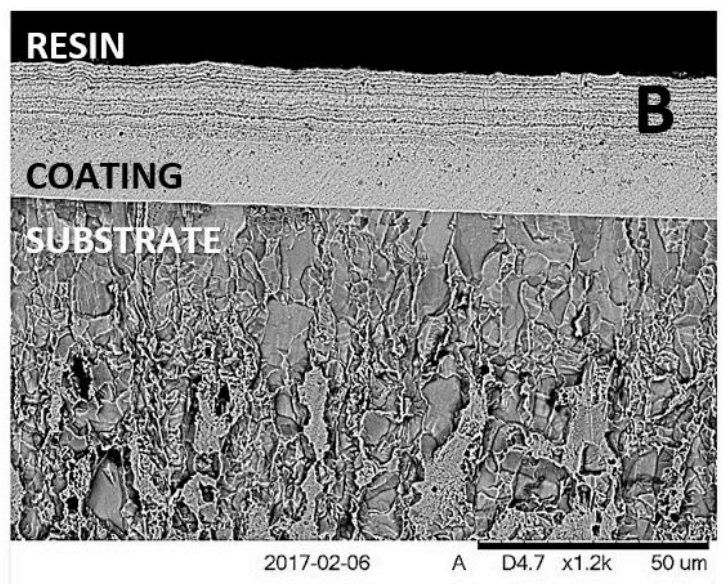

DEMECICTG

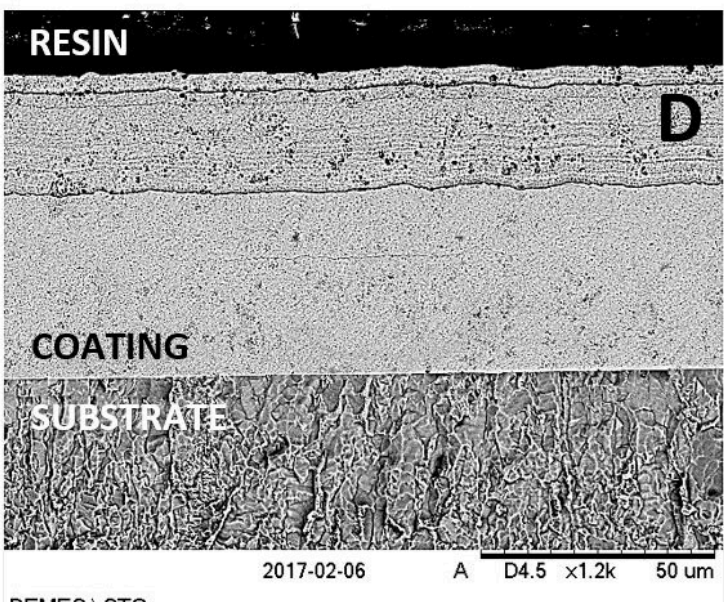

DEMEC $\backslash$ CTG

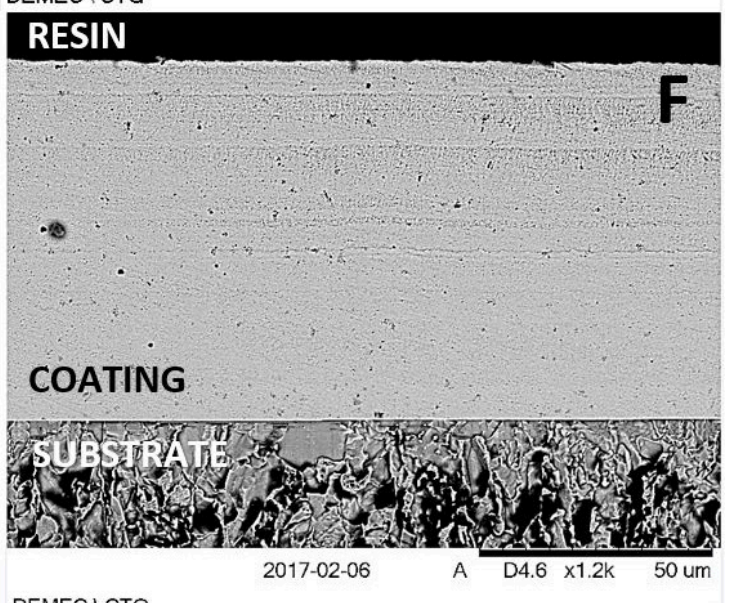

DEMECICTG

Figure 5. SEM micrographs of the cross-section of $\mathrm{Ni}-\mathrm{Co} / \mathrm{SiC}$ nanocomposite coatings, obtained under the cathodic current condition $5.5 \mathrm{~A} \mathrm{dm}^{-2}$ in the intervals: A) $10 \mathrm{~min}$; B) $20 \mathrm{~min}$; C) $30 \mathrm{~min}$; D) $40 \mathrm{~min}$; E) $50 \mathrm{~min}$; F) $60 \mathrm{~min}$. Etching: $1: 1 \mathrm{HNO}_{3}$ and $\mathrm{CH}_{3} \mathrm{COOH}$ solution for $5 \mathrm{~s}$. 
layers with distinct characteristics and porosities in all of the $\mathrm{Ni}-\mathrm{Co} / \mathrm{SiC}$ coating samples. It appears that these intermediate layers formed by more widely spaced lamellae were more frequent in the regions closer to the surface (coating / resin interface). This may indicate that the initially formed layer has spaced lamellae morphology. Plus, it becomes more densified and / or compacted as the upper layer is deposited. The reduction of species and the trapping of $\mathrm{SiC}$ contribute to the increase in the thickness of the coating and the filling of void spaces. Thus, the region closer to the coating / substrate interface presents more refined layers and a more compact morphology. As the deposition time increases, the deeper regions of the coating become more compact than the region closer to the surface. In this case, the deposition time acted both on the growth of the coating, wich probably occurred due to the densification of the layers already deposited as well as on deposition of new layers (Figure 5), favoring the increase in thickness (Figure 4).

The observation of cross-section by SEM led to the investigation of the chemical composition of the constituent layers of the $\mathrm{Ni}-\mathrm{Co} / \mathrm{SiC}$ nanocomposite coating. The analyzes were performed along the coating with depth measurements of $10 \mu \mathrm{m}, 20 \mu \mathrm{m}$ and $30 \mu \mathrm{m}$ and are listed in Table 3 below.

The data shown in Table 3 revealed a variation in the chemical composition of the cross-section of all samples, indicating that the $\mathrm{SiC}$ capture and $\mathrm{Ni}$ and $\mathrm{Co}$ deposition processes are not homogeneous and do not occur at a constant rate. This fact can be explained by the sequence of reactions triggered after the beginning of electrodeposition (Equations 1 to 7 ) and verified by the different surface morphologies that were obtained in the samples at different times of electrodeposition (Figure 1), maintaining the hydrodynamic and current conditions. Analyzing the chemical composition in the cross-section of each sample, the competition between $\mathrm{Ni}^{2+}$ and $\mathrm{Co}^{2+}$ cations is clear since, depending on the depth of the coating, there are regions where cobalt is not the element with the highest content, as would be expected by the anomalous codeposition. These results indicate that the obtained coatings have a non-homogeneous cross-section due to the presence of multiple layers, whose individual characteristics combined should reflect the chemical and mechanical properties analyzed on the surface. It is observed in Table 3 that all samples have regions where the concentration of $\mathrm{SiC}$ is maximum and regions where its concentration is minimal forming a functional gradient. This trend is observed in all studied samples and can be attributed to the different diffusion rates of ionic species and the particle "cloud" throughout the deposition process. A particle distribution gradient in multilayer deposits can lead to the production of improved coatings that have the ability to self-control chemical or physical properties depending on the thickness of the coating ${ }^{12}$. SiC nanoparticles adsorb on the surface of cobalt needle-like structures, expanding the surface area, with subsequent nickel coating, but they can also migrate to more stable sites, reducing the porosity of the coating. The use of multi-layered coatings can be an alternative to reduce porosity because the probability of pores, from different layers, coinciding is low. The increase in the thickness of the coatings layer observed in Figure 4 is also a measure of interest since thicker noble coatings protect the substrate more effectively ${ }^{30}$. Thus, combined with the study of thickness (Figure 4), the use of multi-layer coatings (Figure 5) is a promising tool in several industry fields. These multi-layers have two functions: reducing the number of pores capable of exposing the substrate and changing properties, such as the corrosion mechanism ${ }^{33}$. In addition, it was found that the chemical compositions determined in the cross-section of the deposits (Table 3 ) were different from the values determined on the surface of the coatings (Figure 2). Srivastava et al. also found different chemical compositions between the cross-section and the surface of Ni$\mathrm{Co} / \mathrm{SiC}$ nanocomposite coatings ${ }^{7}$. Lari Baghal, Heydarzadeh Sohi and Amadeh observed a slight decrease in the cobalt content from the bottom to the surface that was associated with a slight depletion of cobalt ions in electrolyte during the electrodepositions ${ }^{15}$. The discovery that the chemical composition of the $\mathrm{Ni}-\mathrm{Co} / \mathrm{SiC}$ nanocomposite coating varied transversely along the cross-section is in line with what has been pointed out in several studies, which analyzed the $\mathrm{Ni}-\mathrm{Co} / \mathrm{SiC}$ nanocomposite coating as a coating formed by a single homogeneous layer, whose Ni-Co matrix has a uniform composition, but presents agglomerated regions of $\mathrm{SiC}^{1,4,15,20}$. Dheeraj et al. performed linear mapping using Energy Dispersive Spectroscopy (EDS) analysis on the cross-section of the $\mathrm{Ni}-\mathrm{Co} / \mathrm{SiC}$ coating obtained by pulsed electrodeposition on a copper substrate ${ }^{34}$. The results revealed

Table 3. Composition of the cross-section of the coatings according to the distance from the surface.

\begin{tabular}{|c|c|c|c|c|c|c|}
\hline \multirow{2}{*}{ Depth } & \multicolumn{6}{|c|}{ Chemical composition (wt. \%) } \\
\hline & Co & $\mathrm{Ni}$ & $\mathrm{SiC}$ & Co & $\mathrm{Ni}$ & $\mathrm{SiC}$ \\
\hline & \multicolumn{3}{|c|}{$10 \mathrm{~min}$} & \multicolumn{3}{|c|}{$20 \mathrm{~min}$} \\
\hline $10 \mu \mathrm{m}$ & 53.53 & 36.33 & 10.14 & 50.58 & 36.35 & 13.06 \\
\hline $20 \mu \mathrm{m}$ & - & - & - & 53.18 & 34.86 & 11.96 \\
\hline \multirow{2}{*}{$30 \mu \mathrm{m}$} & - & - & - & 56.43 & 35.11 & 8.45 \\
\hline & \multicolumn{3}{|c|}{$30 \mathrm{~min}$} & \multicolumn{3}{|c|}{$40 \mathrm{~min}$} \\
\hline $10 \mu \mathrm{m}$ & 44.99 & 43.33 & 11.68 & 51.01 & 29.26 & 19.73 \\
\hline $20 \mu \mathrm{m}$ & 37.05 & 51.43 & 11.52 & 54.50 & 28.09 & 17.38 \\
\hline \multirow[t]{2}{*}{$30 \mu \mathrm{m}$} & 30.64 & 60.84 & 8.52 & 55.00 & 31.57 & 13.39 \\
\hline & \multicolumn{3}{|c|}{$50 \mathrm{~min}$} & \multicolumn{3}{|c|}{$60 \mathrm{~min}$} \\
\hline $10 \mu \mathrm{m}$ & 58.38 & 26.86 & 14.46 & 57.31 & 34.06 & 8.64 \\
\hline $20 \mu \mathrm{m}$ & 54.59 & 32.12 & 13.29 & 57.30 & 35.86 & 6.84 \\
\hline $30 \mu \mathrm{m}$ & 54.31 & 30.14 & 15.55 & 53.60 & 39.93 & 6.57 \\
\hline
\end{tabular}


a very uniform distribution of the elements in all samples. Bakhit et al. proposed to obtain $\mathrm{Ni}-\mathrm{Co} / \mathrm{SiC}$ coatings by galvanostatic deposition using the electrodes positioned horizontally inside the bath, then the elemental line scans showed a fairly uniform distribution of the elements through the thickness of the nanocomposite coatings ${ }^{20}$. Meanwhile, the SEM images indicated a uniform distribution of SiC agglomerates. It is noteworthy that obtaining nanocomposite coatings can be influenced by a series of parameters including particle characteristics (type, dimensions, surface charge and concentration), electrolyte composition (electrolyte concentration, surfactant type and concentration, additives, temperature and $\mathrm{pH}$ ), current density (direct current, pulsed current, reverse pulse current, duty cycle and potentiostatic control), hydrodynamics (laminar, mixed and turbulent regimes), the characteristics of the electrodes (inert, non-inert, rotating disk electrode, rotating cylinder electrode, plate-in-tanks, parallel plate electrodes and many variations) in addition to the type of substrate ${ }^{4,12}$. Many tests have been carried out to investigate the parametric effects on the codeposition of nanoparticles, however, one must also consider the specific conditions restricted to each system used. A clear picture of the exact effect of the experimental parameters is often difficult to obtain due to the correlation among them. The modification in one of the deposition parameters can result in several possibilities such as different mechanical, physical and chemical characteristics ${ }^{8,9,12}$. As it is a low cost technique, the equipment used in electrodeposition is commonly in use, and a series of electrolytes can be used according to the substrate and the desired characteristics for the coating 6,35 . This diversification in the experiments results in an extensive variety of works that bring more and more empirical knowledge and discoveries in the area of nanocomposite coatings obtained by electrodeposition.

\subsection{Micro-hardness}

Figure 6 shows the effect of the deposition time on microhardness and the $\mathrm{SiC}$ content determined on the surface of the $\mathrm{Ni}-\mathrm{Co} / \mathrm{SiC}$ nanocomposite coating.

Comparing the behavior of the micro-hardness and the SiC content of the deposits on the surface shown in Figure 6, it was observed that the two behave similarly in response to the deposition time. The micro-hardness reaches a maximum value within $20 \mathrm{~min}$, followed by a decline to a minimum value within $30 \mathrm{~min}$ and, in the subsequent times, the values oscillated in an intermediate range. The micro-hardness determined on the substrate surface $(252 \mathrm{HV} \pm 8 \mathrm{HV})$ was lower than the values found for all samples, except in the condition at $30 \mathrm{~min}$. Although the samples have thicknesses ranging from $13.2 \mu \mathrm{m}$ to $92.3 \mu \mathrm{m}$, as there was a uniform coverage of the substrate verified by Figure 1, the coatings presented different micro-hardness values than the substrate. Despite the coating obtained within $20 \mathrm{~min}$ being the second thinner (Figure 4), the values of the SiC content and microhardness (Figure 6) were the highest among the samples, indicating that the $\mathrm{SiC}$ content affected more significantly micro-hardness than the thickness of the coating. The reduction in micro-hardness observed within 30 min of deposition can mean a transition from the majority of a nickel layer with a high $\mathrm{SiC}$ content $(20 \mathrm{~min})$ to a cobalt-rich one with a low $\mathrm{SiC}$ content (30 min). Coupled with the lower $\mathrm{SiC}$ content on the sample surface after $30 \mathrm{~min}$, the existence of micro-voids in the deposit structure (Figure 1-C) may have directly influenced the result found. The formation of micro-voids decreases the micro-hardness of metallic matrix composite coatings, which depends mainly on the hardness of the matrix grains and the ceramic particles incorporated in the coating ${ }^{8,20}$. Thus, higher levels of $\mathrm{SiC}$ nanoparticles should produce coatings with higher micro-hardness, using the same metal grain as the Ni-Co matrix. According to Bahadormanesh and Dolati, inherent characteristics of the particles (concentration, spacing, distribution, morphologies and interfaces), the size of the dispersed phase, the structure and the mechanical properties of the matrix are factors that influence the micro-hardness of nanocomposite coatings ${ }^{14}$.

The behavior observed between the micro-hardness values and the $\mathrm{SiC}$ content of the samples surface was similar to that observed by Pereira et al., who associated the micro-hardness with the nanoparticulate $\mathrm{SiC}$ content in Co-Ni/SiC nanocomposite coating electrodeposited in API

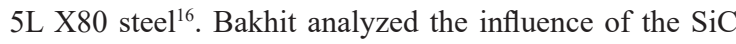
particle size on the nanocomposite structure and tribological properties and found that increasing the concentration of $\mathrm{SiC}$ particles incorporated in the Ni-Co nanocomposite results in increased micro-hardness ${ }^{36}$. Srivastava et al. reported no improvement in the hardness of Ni-Co composites (68 wt.\% $\mathrm{Co})$ reinforced by $\mathrm{SiC}$ nanoparticles and the corresponding alloy (about $300 \mathrm{HV}$ ), despite the fact that changes in the deposit morphology were observed ${ }^{7}$. The authors found that the incorporation of $\mathrm{SiC}$ nanoparticles did not occur satisfactorily and, therefore, did not act correctly as reinforcement in the matrix. The observed correlation between micro-hardness and $\mathrm{SiC}$ content shown in Figure 6 is an indicative of the proper dispersion of nanoparticles in the NiCo matrix on the surface of each sample.

The chemical composition variation in the cross-section (Table 3 ) of the $\mathrm{Ni}-\mathrm{Co} / \mathrm{SiC}$ nanocomposite coating motivated the investigation of micro-hardness in this region and the profiles obtained are shown in Figure 7.

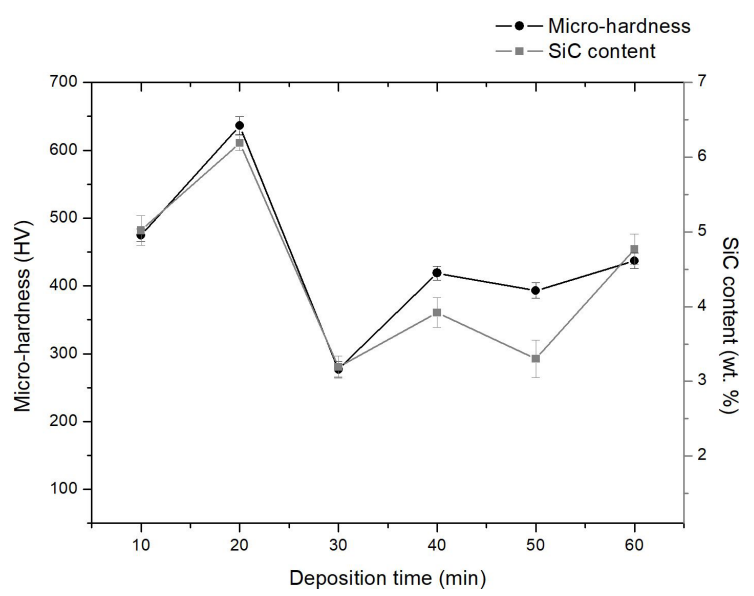

Figure 6. Effect of deposition time on micro-hardness and on the content of $\mathrm{SiC}$ nanoparticles on the surface of the $\mathrm{Ni}-\mathrm{Co} / \mathrm{SiC}$ nanocomposite coating. 


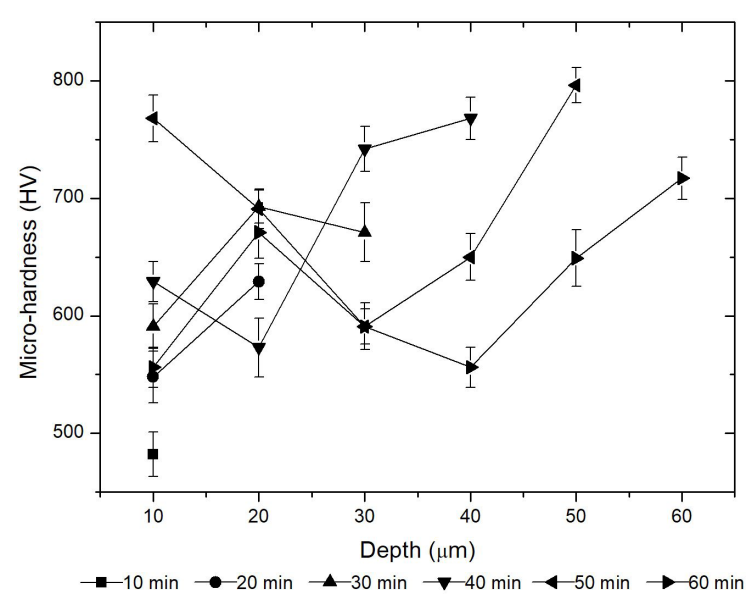

Figure 7. Micro-hardness profile in the cross-section of $\mathrm{Ni}-\mathrm{Co} / \mathrm{SiC}$ nanocomposite coatings as a function of galvanostatic deposition time.

In Figure 7, there is a fluctuation in the micro-hardness values in the cross-section of all samples that can be associated with the functional gradient of each coating (Table 2), instituted by the competition of the active species during the electrodeposition. Comparing the micro-hardness values in the regions closer to the surface to the ones closer to the substrate, it was observed that there was an increase in micro-hardness with depth in all coatings. This increase in micro-hardness in the deepest region of the coating indicates greater densification and compaction, which may be due to species migration during deposition to more energetically favorable sites ${ }^{33}$. Lari Baghal, Heydarzadeh Sohi and Amadeh studied the functional gradient formed in the $\mathrm{Ni}-\mathrm{Co} / \mathrm{SiC}$ nanocomposite coating electrodeposited on aluminum plates using the pulsed current technique ${ }^{15}$. The authors evaluated the micro-hardness profile in the cross-section of the coating and found that the size of the indentations increased as the outer edge distanced. In this case, the authors related the observed behavior to the $\mathrm{SiC}$ content in the cross-section, which was lower in the innermost layers of the deposit.

When comparing the micro-hardness analysis performed on the surface (Figure 6) and on the cross-section (Figure 7) of the coatings, a significant difference is observed between the values. In general, the micro-hardness profile in the cross-section showed higher values than that measured on the surface. Considering that the measurement carried out in the cross-section made it possible to analyze each level of the coating and that the indentations were examined in the direction parallel to the surface, the value found for the surface analysis was the result of the joint contribution of each layer (composition and crystalline structure) and the presence of defects such as micro-voids and $\mathrm{SiC}$ agglomerates. The gradient of chemical composition (Table 2) and the microhardness profile (Figure 7) along the cross-section showed the functional gradient of the $\mathrm{Ni}-\mathrm{Co} / \mathrm{SiC}$ nanocomposite coating obtained by galvanostatic deposition, as well as the formation dynamics and the relationship among multiple layers. These factors resulted in a multilayer $\mathrm{Ni}-\mathrm{Co} / \mathrm{SiC}$ nanocomposite coating, among which the most internal showed a higher degree of densification and therefore lower density of micro-voids.

\section{Conclusions}

The potential for multi-layer formation in the nanocomposite $\mathrm{Ni}-\mathrm{Co} / \mathrm{SiC}$ electrodeposited coating on API 5L X80 steel was studied. The influence of the deposition time on the morphology, microstructure and microhardness was investigated on the surface and in the cross-section of the coatings obtained by galvanostatic deposition, in which the operational parameters of a conventional coating were maintained. SEM-EDS analyzes revealed needle-like structures, rich in cobalt, and structures with a "cauliflower" shape, rich in nickel and $\mathrm{SiC}$ showing that the morphology and chemical composition of the surface of the coatings varied considerably depending on the time of deposition. The formation of the $\mathrm{Ni}-\mathrm{Co} / \mathrm{SiC}$ nanocomposite coating occurred through the initial deposition of a cobalt-rich layer. Hence, this layer acted by lowering the surface energy and promoting roughness for the deposition of a layer rich in nickel, which favored the trapping of SiC nanoparticles. The phenomenon of oscillation between surfaces rich in cobalt and nickel was observed in the subsequent layers, constituting a functional coating gradient. As a result, the different $\mathrm{Ni}-\mathrm{Co} /$ $\mathrm{SiC}$ nanocomposite coatings produced presented a different chemical composition in the cross-section, the thickness of which was formed from dense and refined structures. The multiple and intermediate layers had different characteristics and porosity. Despite the morphological and compositional differences depending on the deposition time, the coatings obtained exhibited preferential orientation of the plane (220) and FCC phase structure. The grain size was reduced with an increase in the $\mathrm{SiC}$ content on the coating surface. The Vickers micro-hardness determined on the surface of the coatings showed a correlation with the $\mathrm{SiC}$ content and the values found in the cross-section varied according to the depth.

Keeping the cathodic current density constant at 5.5 $\mathrm{A} \mathrm{dm}^{-2}$ and the operational parameters for obtaining a conventional nanocomposite coating, the galvanostatic electrodeposition process triggered a series of reactions that control the deposition mechanism and resulted in a Ni$\mathrm{Co} / \mathrm{SiC}$ nanocomposite coating with a functional gradient composed of multiple layers.

\section{Acknowledgements}

The authors thank CNPq (Conselho Nacional de Desenvolvimento Científico e Tecnológico), Petrobras and Finep for the financial and structural support in the development of this work. To the Department of Physics of the UFPE for the concession of the analysis in the SEM.

\section{References}

1. Jiang W, Shen L, Xu M, Wang Z, Tian Z. Mechanical properties and corrosion resistance of $\mathrm{Ni}-\mathrm{Co}-\mathrm{SiC}$ composite coatings by magneticfield-induced jet electrodeposition. J Alloys Compd. 2019;791:847-55.

2. Wang Y, Zhou X, Liang Z, Jin H. Characterization of ultrasonicassisted electrochemical deposition of Ni-Co- $\mathrm{ZrO}_{2}$. Coatings. 2018;8(6):211.

3. Torabinejad V, Rouhaghdam AS, Aliofkhazraei M, Allahyarzadeh $\mathrm{MH}$. Electrodeposition of $\mathrm{NieFe}$ and $\mathrm{NieFe}-\left(\right.$ nano $\mathrm{Al}_{2} \mathrm{O}_{3}$ ) multilayer coatings. J Alloys Compd. 2016;657:526-36. 
4. Yang Y, Cheng YF. Electrolytic deposition of Ni-Co-SiC nanocoating for erosion-enhanced corrosion of carbon steel pipes in oilsand slurry. Surf Coat Tech. 2011;205:3198-204.

5. Garcia-Lecina E, Garcia-Urrutia I, Diez JA, Salvo M, Smeacetto F, Gautier G, et al. Electrochemical preparation and characterization of $\mathrm{Ni} / \mathrm{SiC}$ compositionally graded multilayered coatings. Electrochim Acta. 2009;54:2556-62.

6. Bard AJ, Faulkner LR. Electrochemical methods: fundamentals and applications. 2nd ed. Hoboken: John Wiley \& Sons; 2001.

7. Srivastava M, Balaraju JN, Ravisankar B, Anandan C, Grips VKW. Influence of SiC particle size on the structure and tribological properties of Ni-Co composites. Surf Coat Tech. 2012;263:310-8.

8. Ma C, Zhao D, Ma Z. Effects of duty cycle and pulse frequency on microstructures and properties of electrodeposited $\mathrm{Ni}-\mathrm{Co}-$ SiC nanocoatings. Ceram Int. 2020;46:12128-37.

9. Dryden DM, Sun T, Mccormick R, Hickey R, Vidu R, Stroeve P. Anomalous Deposition of Co-Ni Alloys in Film and Nonowire Morphologies from Citrate Baths. Electrochim Acta. 2016;220:595-600.

10. Özkan S, Hapçi G, Orhan G, Kazmanli K. Electrodeposited $\mathrm{Ni} / \mathrm{SiC}$ nanocomposite coatings and evaluation of wear and corrosion properties. Surf Coat Tech. 2013;232:734-41.

11. Allahyarzadeh MH, Aliofkhazraei M, Sabour Rouhaghdam AR, Torabinejad V. Gradient electrodeposition of Ni-Cu-W(alumina) nanocomposite coating. Mater Des. 2016;107:74-81.

12. Low CTJ, Wills RGA, Walsh FC. Electrodeposition of composite coatings containing nanoparticles in a metal deposit. Surf Coat Tech. 2006;201:371-83.

13. Vereschaka A, Tabakov V, Grigoriev S, Sitnikov N, Oganyan $\mathrm{G}$, Andreev N, et al. Investigation of wear dynamics for cutting tools with multilayer composite nanostructured coatings in turning constructional steel. Wear. 2019;(420-421):17-37.

14. Bahadormanesh B, Dolati A. The kinetics of $\mathrm{Ni}-\mathrm{Co} / \mathrm{SiC}$ composite coatings electrodeposition. J Alloys Compd. 2010;504(2):514-8.

15. Lari Baghal SM, Heydarzadeh Sohi M, Amadeh A. A functionally gradiente nano- $\mathrm{Ni}-\mathrm{Co} / \mathrm{SiC}$ composite coating on aluminium and its tribological properties. Surf Coat Tech. 2012;206:4032-9.

16. Pereira RFC, Oliveira ESD, Vieira MRS, Lima MAGA, Urtiga SLFo. Evaluation of Co-Ni/SiC nanocomposite coating obtained by electrodeposition on the corrosion resistance of API 5L X80 steel. Mater Res. 2017;20(suppl 2):221-30.

17. Devaneyan SP, Senthilvelan T. Electro co-deposition and characterization of $\mathrm{SiC}$ in nickel metal matrix composite coatings on Aluminium 7075. Procedia Eng. 2014;97:1496-505.

18. Crousier J, Eyraud M, Crousier JP, Roman JM. Influence of substrate on the electrodeposition of nickel-molybdenum alloys. J Appl Electrochem. 1992;22(8):749-55.

19. Yang Y, Cheng YF. Fabrication of Ni-Co-SiC composite coatings by pulse electrodeposition - Effects of duty cycle and pulse frequency. Surf Coat Tech. 2013;216:282-8.

20. Bakhit B, Akbari A, Nasirpouri F, Hosseini MG. Corrosion resistance of Ni-Co alloy and $\mathrm{Ni}-\mathrm{Co} / \mathrm{SiC}$ nanocomposite coatings electrodeposited by sediment codeposition technique. Appl Surf Sci. 2014;307:351-9.

21. ASTM International. ASTM B748 - 90: Standard Test Method for Measurement of Thickness of Metallic Coatings by Measurement of Cross Section with a Scanning Electron Microscope. West Conshohocken: ASTM International; 2016.

22. Calberto SA. Nickel matrix micro/nano SiC composite electrodeposition [projecto final de carrera]. Barcelona: Escola Tecnica Superior D'Engyneria Industrial de Barcelona; 2011.

23. Rudnik E, Syrek S. Studies on the codeposition of SiC nanopowder with nickel, cobalt, and Co-Ni alloys. Journal of Coatings. 2014;2014(659697):1-10.

24. Chen L, Wang L, Zeng Z, Xu T. Influence of pulse frequency on the microstructure and wear resistance of electrodeposited $\mathrm{Ni}-\mathrm{Al}_{2}-\mathrm{O}_{3}$ composite coatings. Surf Coat Tech. 2006;201(34):599-605.

25. ASTM International. ASTM E384 - 11e1: Standard Test Method for Knoop and Vickers Hardness of Materials. West Conshohocken: ASTM International; 2011.

26. Kharmachi I, Dhouibi L, Berçot P, Rezrazi M. Co-deposition of $\mathrm{Ni}-\mathrm{Co}$ alloys on carbon steel and corrosion resistance. Journal of Materials and Environmental Science. 2015;6(7):1807-12.

27. Strmcnik D, Lopes PP, Genorio B, Stamenkovic VR. Design principles for hidrogen evolution reaction catalyst materials. Nano Energy. 2016;29:29-36.

28. Ignatova $\mathrm{K}$, Lilova D. A study on the kinetics of the electrodeposition of Ni, Co and Ni-Co alloy in citrate electrolyte. Part 1: the kinetic study of the independent electrodeposition of $\mathrm{Ni}$ and $\mathrm{Co}$. Journal of Chemical Technoloy and Metallurgy. 2015;50(2):199-206.

29. Bai A, Hu CC. Effects of electroplating variables on the composition and morpholoy of nickel/cobalt deposits plated through means of cyclic voltammetry. Electrochim Acta. 2002;47:3447-56.

30. Panossian Z. Manual: corrosão e proteção contra a corrosão em equipamentos e estruturas metálicas. Vol. 2. São Paulo: Instituto de Pesquisas Tecnológicas; 1993.

31. Brenner A. Electrodeposition of alloys: principles and practice. Vol. 1. New York-London: Academic Press, 1963.

32. Guglielmi N. Kinetics of the deposition of inert particles from electrolytic baths. J Electrochem Soc. 1972;119(8):1009-12.

33. Brett AMO, Brett CMA. Electroquimica - principios, metodos e aplicaçoes. Coimbra: Editora Almedina; 2000.

34. Dheeraj PR, Patra A, Sengupta S, Das S, Das K. Synergistic effect of peak current density and nature of surfactant on microstructure, mechanical and electrochemical properties of pulsed electrodeposited Ni-Co-SiC nanocomposites. J Alloys Compd. 2017;729:1093-107.

35. Prasad S. Otimização e controle de banhos para a eletrodeposição de ligas [tese]. Campina Grande: Universidade Federal de Campina Grande; 1996.

36. Bakhit B. The influence of electrolyte composition on the properties of Ni-Co alloy coating reinforced by $\mathrm{SiC}$ nanoparticles. Surf Coat Tech. 2015;274:324-31. 